\title{
Analysis of T Cell Receptor V $\beta$ Diversity in Peripheral CD4+ and CD8+ T Lymphocytes Obtained From Patients With Chronic Severe Hepatitis B
}

\author{
Ying Xiong ${ }^{1,2}$; Yan $\operatorname{Tan}^{1,3,{ }^{*}}$; Yu Guo Song ${ }^{2}$ \\ ${ }^{1}$ Central Laboratory, First Affiliated Hospital, Jilin University, Changchun, China \\ ${ }_{2}^{2}$ Life Science Research Center, Beihua University, Jilin, China
${ }^{3}$ Cancer Biotherapy Center, Jilin Province People's Hospital, Changchun, China \\ ${ }^{*}$ Corresponding Author: Yan Tan, Central Laboratory, First Affiliated Hospital, Jilin University, 130000, Changchun, China. Tel: +86-85595097, Fax: $+86-85595097$, E-mail:
} tanyan1956@126.com

Received: November 2, 2013; Revised: December 9, 2013; Accepted: December 15, 2013

\begin{abstract}
Background: The hepatitis B virus (HBV) antigen-induced cellular immune response plays an important role in HBV clearance. Changes in the diversity of complementarity determining region 3 (CDR3) and T-cell receptor (TCR) sequences are used to monitor the response of T cells to antigens.

Objectives: The aim of the present study was to determine whether the TCR V $\beta$ repertoire of patients with chronic severe hepatitis B (CSHB) undergoes increased stimulation, and to identify conserved motifs in specific TCR V $\beta$ families.

Patients and Methods: Peripheral blood mononuclear cells(PBMCs) from 18 patients with CSHB were sorted into CD4+and CD8+Tsubsets, using monoclonal antibody-coated magnetic beads. The TCR V $\beta$ CDR3 was subsequently characterized using immune spectratyping. The TCR V $\beta$ families exhibiting a CDR3 spectratype that underwent monoclonal expansion were sequenced.

Results: The number of oligoclonal or monoclonal expansion TCR V $\beta$ families detected in the analyzed CD8+ T cells was significantly higher than the number detected in CD4+ T cells. The CDR3 spectratype analysis showed predominant usage of TCR VB5, VB7, VB9, V V12, and V 818 families in CD8+ T cell subsets of CSHB patients. Furthermore, conserved amino acid motifs were found to be associated with the monoclonal expansion of CD8+ TCR V $\beta$ families. In addition, JB1S1 and JB2S7 region genes were present at a high frequency.

Conclusions: The CD4+ and CD8+ TCR V $\beta$ gene families undergo clonal expansion in CSHB patients, and CD 8+ T cells play a major role in the pathogenesis of CSHB. Moreover, the conserved motifs and limited use of joining region genes observed in the CSHB patients of this cohort indicated that similar antigenic epitopes are recognized.
\end{abstract}

Keywords: Hepatitis B; Genes, T-Cell Receptor; CD8-Positive T-Lymphocytes; Complementarity Determining Regions; Clonal expansion; Immunity, Cellular

\section{Background}

Hepatitis B virus (HBV) infection is a major health problem worldwide. While some individuals, who develop an acute HBV infection, can clear the virus and achieve lifelong immunity, others develop a chronic HBV infection. The latter is associated with various clinical manifestations ranging from an asymptomatic carrier state, with normal liver histology, to severe and chronic liver disease, including cirrhosis and hepatocellular carcinoma (HCC) $(1,2)$. A mortality rate greater than $50 \%$ is reported for those who develop chronic severe hepatitis B (CSHB) $(3,4)$.

The HBV antigen-induced cellular immune response plays an important role in HBV clearance (5). This response involves both major histocompatibility complex
(MHC) class II-restricted CD4+ helper T cells and MHC class I-restricted CD8+ cytotoxic T lymphocytes. Correspondingly, the pathogenesis of CSHB has been shown to be related to significant increases in the levels of CD8+ and nonspecific T cells (6). While CD4+ T cells do not directly participate in viral clearance and tissue damage, it is hypothesized that they indirectly control HBV infection by facilitating the induction and maintenance of virus-specific B cells and the CD8+ T cell response (7).

$\mathrm{T}$ cells recognize antigens by binding $\mathrm{T}$ cell receptors (TCRs) present on the surface of lymphocytes. Approximately $95 \%$ of CD4+ and CD8+ T cells are composed of an $\alpha$ - and $\beta$-chain, and the $\beta$-chain gene complex of the human TCR includes at least 57 variable $(V)$ gene segments. These gene segments have been further divided into 24 TCR V $\beta$ gene families. The hypervariable region of

Implication for health policy/practice/research/medical education:

The results provide evidence that peripheral CD4+ and CD8+ T cells from chronic severe hepatitis B (CSHB) patients have undergone clonal expansion The detection of pathogenic T cells in CSHB patients also provides useful information regarding the pathogenesis and status of this disease. It is expected that the results of the present study would facilitate the development of DNA vaccines and individualized immunotherapies for CHSB, especially when combined with future studies to characterize the conserved sequence motifs identified.

Copyright (C) 2014, Kowsar Corp;; Published by Kowsar Corp. This is an open-access article distributed under the terms of the Creative Commons Attribution License, which permits unrestricted use, distribution, and reproduction in any medium, provided the original work is properly cited. 
each TCR V $\beta$ family, referred to as the complementaritydetermining region 3 (CDR3), is formed by joining V-D-J segments. These recombination events then establish the diversity of the immune responses manifested by individuals.

The CDR3 is one of the three regions, which determine $\mathrm{T}$ cell antigen specificity. Therefore, changes in CDR3 diversity and TCR sequences are used to monitor the response of T cells to antigens. In particular, spectratyping is a widely used technique able to measure the TCR repertoire diversity based on variations in the lengths of the reverse transcriptase-PCR (RT-PCR) products generated (8). Thus, spectratyping represents an important tool for monitoring antigen-driven clonal expansion or depletion of T lymphocytes. Correspondingly, immune spectratyping has been widely used in the recent years to detect the clonal features of T cells and to analyze the TCR CDR3 gene $(9,10)$.

While accumulating evidence has suggested that clonal expansion of $\mathrm{T}$ cells plays a major role in the immune pathogenesis of patients with chronic hepatitis $B$ (CHB), only a few studies have described the individual TCR clonal features of CD4+ and CD8+ T cell subsets for patients with CSHB (11). In this study, the CD4+ and CD8+ TCR V $\beta$ repertoire from 18 CSHB patients were analyzed, using immunoscope spectratyping. It is hypothesized that characterization of the CDR3 spectratypes of the 24 $\mathrm{V} \beta$ families would provide valuable insight into the development of DNA vaccines and individualized immunotherapies for CSHB (12).

\section{Objectives}

The aim of the present study was to determine whether the TCR V $\beta$ repertoire of patients with CSHB undergoes increased stimulation, and to identify conserved motifs in specific TCR V $\beta$ families.

\section{Patients and Methods}

\subsection{Subjects}

Eighteen CSHB patients with positive results for HBV antigens for at least 12 mo were admitted to the Department of Infectious Disease (First Affiliated Hospital, Beihua University, Jilin, China) between March 2011 and May 2012, and were enrolled in this study. These patients included 14 males and four females, with a mean age of $32.5 \pm 1.2 \mathrm{y}$ (range: 18-50). Eight age-matched healthy control donors were also included in this study. Both patients and donors provided written informed consent. Peripheral blood samples were obtained from each patient and healthy control. The presence of human immunodeficiency virus (HIV), hepatitis A virus (HAV), hepatitis C virus (HCV), hepatitis D virus (HDV), and hepatitis E virus (HEV) were excluded by laboratory testing. In addition, patients with
CSHB had serum alanine aminotransferase (ALT) levels greater than $40 \mathrm{IU} / \mathrm{L}$, total bilirubin (TBIL) levels greater than $170 \mu \mathrm{mol} / \mathrm{L}$, and plasma prothrombin activity (PTA) levels less than $40 \%$ (13). This study was conducted according to the guidelines of the Declaration of Helsinki, and the Beihua University Medical Ethics Committee approved all procedures involving human subjects.

\subsection{Serological Markers and Biochemical Evalua- tion}

Serum ALT and TBIL levels were detected using an automatic biochemical analyzer (HITACHI 7080, Khiyoda, Tokyo, Japan). Enzyme-linked immunosorbent assay (ELISA) detection kits (Jingmei Biotech, Shenzhen, China) were used to detect HBV markers: HBsAg, HBeAg, HBeAb, and HBcAb.

\subsection{Quantification of Serum HBVDNA}

A quantitative real-time fluorescence kit (Shenzhen PG Biotech, Shenzhen, China) was used to quantify serum HBV DNA levels. The lower limit of detection for this kit was 1000 viral genome copies $/ \mathrm{mL}$.

\subsection{Isolation of CD4+ and CD8+ T lymphocytes}

Peripheral blood mononuclear cells (PBMCs) were isolated from the heparinized whole blood samples collected from CSHB patients $(\mathrm{n}=18)$ using Ficoll-Hypaque gradient centrifugation (GE healthcare-science AB, Uppsala, Sweden). The CD4+ and CD8+ T lymphocytes were purified from PBMCs using monoclonal antibody-coated magnetic beads according to the manufacturer's instructions (Invitrogen Dynal AS, Oslo, Norway). Briefly, an appropriate volume of CD4+/CD8+ Dynabeads was added to each tube containing a PBMC sample. After $20 \mathrm{~min}$ at $4^{\circ} \mathrm{C}$ with gentle tilting and rotation, the tubes were placed in a magnetic rack for $2 \mathrm{~min}$ to isolate each supernatant. After the supernatants were discarded, the beads were washed three times. Using flow cytometry, the purity of each isolated cell population was found to be greater than 90\% (Beckman Coulter XL, Brea, CA, The USA).

\subsection{Extraction of RNA and Synthesis of $C D N A$}

Total RNA was extracted from $1 \times 105$ to $5 \times 105$ CD4+ / CD8+ T lymphocytes using a total RNA extraction kit (Promega, Madison, WI, The USA), according to the manufacturer's instructions. Purified RNA was subsequently quantified using spectrophotometry. To synthesize firststrand cDNA, $1 \mu \mathrm{g}$ total RNA was combined with $250 \mathrm{uM}$ oligo dT (Promega, Madison, WI, The USA), 200 U M-MLV reverse transcriptase (Promega, Madison, WI, The USA), and $250 \mathrm{uM}$ of each deoxyribonucleoside triphosphate (dNTP) (Promega, Madison, WI) in a total volume of $20 \mathrm{uL}$. Synthesis was performed at $42^{\circ} \mathrm{C}$ for $60 \mathrm{~min}$, and then the 
reaction was terminated at $72^{\circ} \mathrm{C}$ for $10 \mathrm{~min}$.

\subsection{PCR Amplification of CDR3 $c D N A$}

Using a two-step PCR assay, CDR3 length within the TCR $\mathrm{V} \beta$ chain was analyzed. The first round of amplification included $0.5 \mathrm{uL}(20 \mathrm{uM}$ ) each of forward $\mathrm{V} \beta$ and reverse $\mathrm{C} \beta$ primers previously described by Kou et al. (14), $0.5 \mathrm{uL}$ (10 mM) dNTPs, 0.25 uL cDNA, 2.5 uL $10 \times$ PCR buffer, and 1.25 U Taq polymerase for a total reaction volume of 25 $\mathrm{uL}$ in sterile $\mathrm{H} 2 \mathrm{O}$. These samples were then subjected to PCR amplification as follows: $3 \mathrm{~min}$ at $95^{\circ} \mathrm{C}$, 35 cycles of $95^{\circ} \mathrm{C}$ for $45 \mathrm{~s}, 55^{\circ} \mathrm{C}$ for $45 \mathrm{~s}$, and $72^{\circ} \mathrm{C}$ for $45 \mathrm{~s}$, followed by a final extension step at $72^{\circ} \mathrm{C}$ for $5 \mathrm{~min}$. The resulting product was then used as the template for a second round of PCR amplification. For the second step, the forward and reverse primers used (V $\beta N S$ and $C \beta N S$, respectively) were designed to bind 3 ' to the first round $V \beta$-specific primer and 88 bp away from the CDR3 region, respectively. In addition, the reverse primer contained a nontemplate sequence, GTTTCTT, which was labeled with a blue fluorescent dye, 6-carboxyfluorescein (6-FAM). After an initial denaturing step at $95^{\circ} \mathrm{C}$ for $3 \mathrm{~min}, 30$ cycles of $95^{\circ} \mathrm{C}$ for $30 \mathrm{~s}, 58^{\circ} \mathrm{C}$ for $30 \mathrm{~s}$, and $72^{\circ} \mathrm{C}$ for $30 \mathrm{~s}$ were performed, followed by a final extension step at $72^{\circ} \mathrm{C}$ for $10 \mathrm{~min}$. An aliquot of each PCR product ( $5 \mathrm{uL}$ ) was subsequently analyzed by agarose electrophoresis. After staining the gel with ethidium bromide, bands present were visualized under ultraviolet light.

\subsection{Analysis of CDR3 Length by Spectratyping}

Fluorescent PCR products and a size marker were mixed with formamide and denatured at $94^{\circ} \mathrm{C}$ for $2 \mathrm{~min}$. Samples were then loaded onto a $6 \%$ acrylamide sequencing gel (National Diagnostic, Atlanta, GA, The USA) and sequenced using a 24-lane Applied Biosystems model 373 DNA sequencer (Applied Biosystems, Foster City, CA, The USA). After $6 \mathrm{~h}$, the data were analyzed and quantified using the ABIPRISM GeneScan analysis software (Applied Biosystems, Foster City, CA, The USA). The relative intensity (RI) of each product was used to generate a curve for each $\mathrm{V} \beta$ family with relative fluorescence intensity calculated as follows: $10 \times$ (clonal peak area) / (total peak area). Monoclonal versus oligoclonal T cell expansion was distinguished according to the presence of a single peak with an RI greater than 35\% or two peaks, each with an RI greater than $25 \%$, respectively.

\subsection{Molecular Cloning and Sequencing of CDR3 Segments}

First-round PCR products were amplified using forward and reverse V $\beta$ PCR primers, which were not fluorescently labeled. The PCR products were then separated using agarose gel electrophoresis and individual bands were purified using a gel extraction kit (Qiagen, Valencia, CA,
The USA) according to the manufacturer's recommendations. The resulting DNA was directly cloned into TA cloning vector PCR 2.1 (Invitrogen, Carlsbad, CA, The USA), sequenced using fluorescent dideoxy terminators, and analyzed using the Applied Biosystems model 337A automated sequencer. The amino acid sequence of the CDR3 region was analyzed using DNAMAN software version 1.0 (Lynnon Biosoft, Pointe-Claire, Quebec, Canada).

\subsection{Statistical Analysis}

Statistical analyses were performed using SPSS 16.0 software (SPSS Inc., Chicago, IL, The USA). Differences between CD4+ and CD8+ T cell datasets were examined using the $\chi^{2}$-test. A P value $<0.05$ was considered statistically significant.

\section{Results}

\section{1. $C D 4+$ and $C D 8+T$ cell Clonality in CSHB Pa- tients}

The CDR3 spectratypes determined for the 18 CSHB patients and eight healthy controls were compared. All of the healthy controls exhibited normally diversified TCR repertoires, with the TCR V $\beta$ gene sequences having a Gaussian distribution of approximately eight peaks. The CD4+ and CD8+ TCR CDR3 spectratype profiles obtained for a healthy control are shown in Figure 1. For the CSHB patients, monoclonal or oligoclonal expansion was detected in 18/18 CD8+ and 16/18 CD4+ samples (Table 1). Furthermore, the number of monoclonal and oligoclonal TCR V $\beta$ families in the CD8+ T cell subsets assayed was higher than that of the CD4+ T cell subsets $(\mathrm{P}<0.01)$. Conversely, the number of normal TCR V $\beta$ family expansions that occurred in CD4+ $\mathrm{T}$ cell subsets was higher than that of the CD8+ T cell subsets ( 2 vs. 0 , respectively) $(\mathrm{P}<$ 0.05). An analysis of $\mathrm{T}$ cell clonality among the 18 CSHB patients also identified certain TCR V $\beta$ families that were more prevalent, including: V $\beta 5$ (27.8\%), V $\beta 7$ (44.4\%), V $\beta 9$ (27.8\%), V $\beta 12$ (50.0\%), and V $\beta 18$ (27.8\%) (Table 2). The CD4+ and CD8+ TCR CDR3 spectratype profiles obtained for a representative patient are shown in Figure 2.

\subsection{Sequence Analysis of the TCR V $\beta$ Chain CDR3 Region}

Using Genescan, the PCR products for the TCR V $\beta$ CDR3 amplified from CD8+ T cells showing monoclonal expansion were cloned, sequenced, and translated. An analysis of these sequences detected a high frequency of the J gene segments, J $\beta 1 S 1$ and J $\beta 2 S 7$. In addition, three amino acid motifs, GSF, LF, and GS were found to be conserved (Table 3). In contrast, no amino acid motifs were found to be conserved in the TCR CDR3 region of the analyzed CD4+ T cells. 


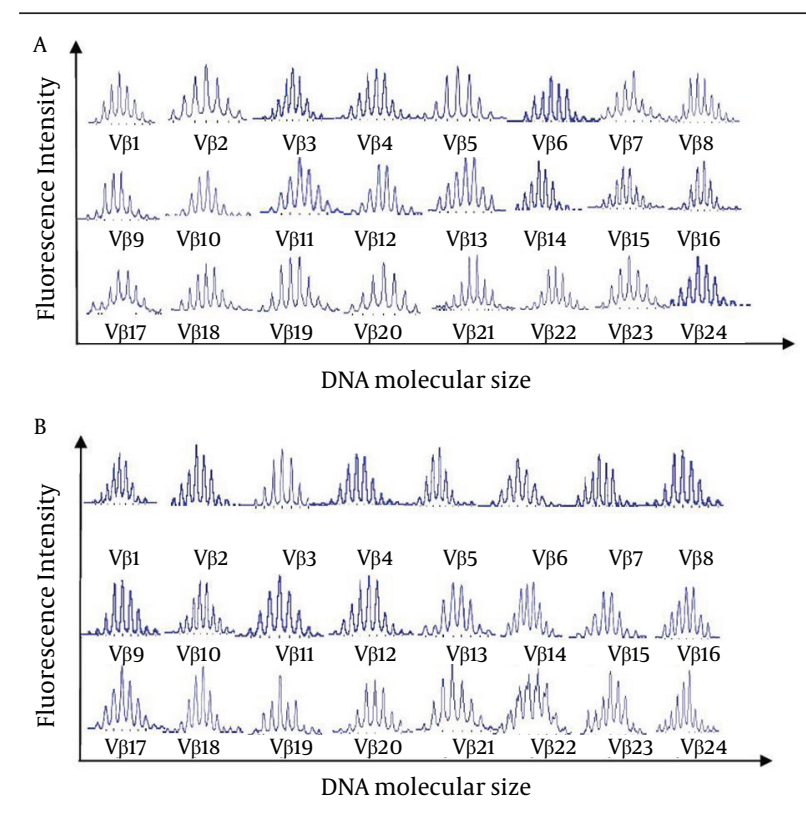

Figure 1. CDR3 Spectratypes of 24 TCR V $\beta$ Families Detected in (A) CD4+ T Cells and (B) CD8 + T Cells Obtained From a Healthy Control (No.1)

Table 1. Oligoclonal or Monoclonal TCR V $\beta$ Families of $C D 4+\mid$ CD8+ T Cell Subsets Detected for 18 CSHB Patients

\begin{tabular}{|c|c|c|c|c|}
\hline \multirow[t]{2}{*}{ Patients } & \multicolumn{2}{|c|}{$\begin{array}{c}\text { CD4+ T Lymphocytes } \\
\left(\mathbf{n}=25^{\mathrm{a}}\right)\end{array}$} & \multicolumn{2}{|c|}{$\begin{array}{c}\text { CD8+ T Lymphocytes } \\
\left(n=49^{\mathrm{a}, \mathrm{b}}\right)\end{array}$} \\
\hline & $\begin{array}{l}\text { Oligo- } \\
\text { clone }\end{array}$ & $\begin{array}{l}\text { Mono- } \\
\text { clone }\end{array}$ & $\begin{array}{l}\text { Oligo- } \\
\text { clone }\end{array}$ & $\begin{array}{l}\text { Mono- } \\
\text { clone }\end{array}$ \\
\hline 1 & 9 & 12,21 & None & $7,9,18$ \\
\hline 2 & None & 15 & None & 11,16 \\
\hline 3 & 9 & None & 8 & $5,7,12$ \\
\hline 4 & 4 & 8 & 7 & $9,12,17$ \\
\hline 5 & None & 12,18 & None & 12,15 \\
\hline 6 & 7 & 8 & 5 & $11,12,18$ \\
\hline 7 & 3 & None & 12 & None \\
\hline 8 & 2 & 7,12 & None & 7,12 \\
\hline 9 & None & 21 & 2 & 8,12 \\
\hline 10 & 9 & None & None & 7,21 \\
\hline 11 & 11 & None & 4 & 5,9 \\
\hline 12 & 5 & None & 5 & 7,18 \\
\hline 13 & None & 5 & 20 & 12 \\
\hline 14 & None & None & 4,5 & 9,21 \\
\hline 15 & None & 9,22 & 2 & 9 \\
\hline 16 & 8 & 11 & 6 & 12,18 \\
\hline 17 & None & None & 11 & 7 \\
\hline 18 & 18 & None & 7 & 18,21 \\
\hline
\end{tabular}

Table 2. The Frequency of Oligoclonal and Monoclonal TCR V $\beta$ Families in CD4+ and CD8+ T Cell Subsets Obtained from 18 CSHB Patients ${ }^{a}$

\begin{tabular}{|c|c|c|}
\hline TCR V $\beta$ Families & $\begin{array}{l}\text { CD4+ T Cell Inci- } \\
\text { dence, }\left(n=25^{b}\right)\end{array}$ & $\begin{array}{l}\text { CD8+ T Cell Inci- } \\
\text { dence, }\left(n=49^{c}\right)\end{array}$ \\
\hline 1 & 0 & 0 \\
\hline 2 & $1(6.25)$ & $2(11.1)$ \\
\hline 3 & $1(6.25)$ & 0 \\
\hline 4 & $1(6.25)$ & $2(11.1)$ \\
\hline 5 & $2(12.5)$ & $5(27.8)$ \\
\hline 6 & 0 & $1(5.56)$ \\
\hline 7 & $2(12.5)$ & $8(44.4)$ \\
\hline 8 & $3(18.8)$ & $2(11.1)$ \\
\hline 9 & $4(25.0)$ & $5(27.8)$ \\
\hline 10 & 0 & 0 \\
\hline 11 & $2(12.5)$ & $3(16.7)$ \\
\hline 12 & $3(18.8)$ & $9(50.0)$ \\
\hline 13 & 0 & 0 \\
\hline 14 & 0 & 0 \\
\hline 15 & $1(6.25)$ & $1(5.56)$ \\
\hline 16 & 0 & $1(5.56)$ \\
\hline 17 & 0 & $1(5.56)$ \\
\hline 18 & $2(12.5)$ & $5(27.8)$ \\
\hline 19 & 0 & 0 \\
\hline 20 & 0 & $1(5.56)$ \\
\hline 21 & $2(12.5)$ & $3(16.7)$ \\
\hline 22 & $1(6.25)$ & 0 \\
\hline 23 & 0 & 0 \\
\hline 24 & 0 & 0 \\
\hline \multicolumn{3}{|c|}{$\begin{array}{l}\text { a The average rate of monoclonal or oligoclonal expansion by TCR V } \\
\text { families in the CD8+ T cell subsets was significantly higher than that for } \\
\text { the CD4+T cell subsets. } \\
\text { b Average ratio for a case: } 1.56 \text {. } \\
\text { c Average ratio for a case: } 2.72 \text {. }\end{array}$} \\
\hline
\end{tabular}




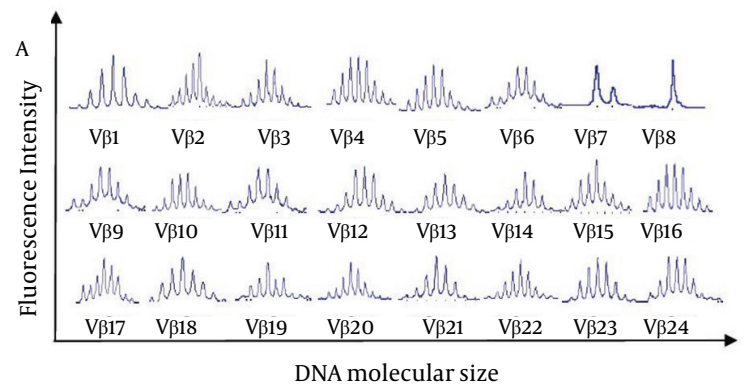

B

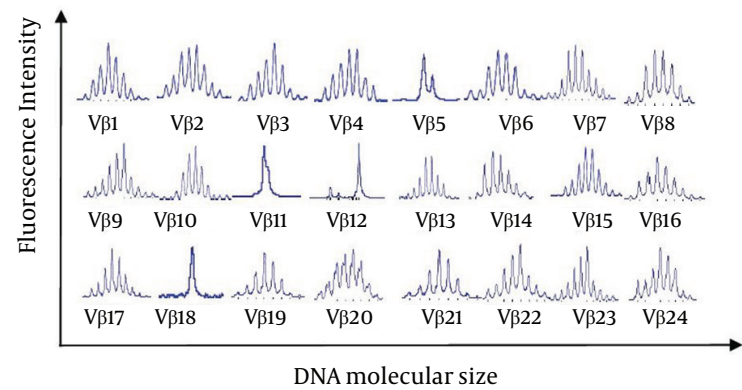

Figure 2. CDR3 Spectratypes of 24 TCR V $\beta$ Families Detected in (A) CD4+ T Cells and (B) CD8+ T Cells Obtained from a CSHB Patient (No. 6)

Table 3. Partial Sequences of the CD8+ TCR CDR3 $\beta$-chain Showing Evidence of Monoclonal Expansion

\begin{tabular}{|c|c|c|c|c|}
\hline Patients & $\mathbf{B V}^{\mathrm{a}}$ & $3^{\prime} V_{\beta}{ }^{a}$ & N-D-N ${ }^{a}$ & $5^{\prime} J \beta^{a}$ \\
\hline 1 (CD8) & 7 & CASS & CPAGSFF $^{\mathrm{b}}$ & TCRBJ1S1 \\
\hline 3 (CD8) & 7 & CASS & TGSFFTAQ & TCRBJ2S7 \\
\hline 8 (CD8) & 7 & CASS & DKGSFG & TCRBJ2S7 \\
\hline 10 (CD8) & 7 & CASS & EAGAAGSF & TCRBJ2S2 \\
\hline 12 (CD8) & 7 & CASS & SSPYGSFF & TCRBJ1S2 \\
\hline 17 (CD8) & 7 & CASS & TGSFGP & TCRBJ1S1 \\
\hline 1 (CD8) & 9 & CASS & GVFDLFG & TCRBJ1S1 \\
\hline 4 (CD8) & 9 & CASS & MILFSQBR & TCRBJ1S1 \\
\hline 11 (CD8) & 9 & CASS & DDVRFG & TCRBJ1S1 \\
\hline 14 (CD8) & 9 & CASS & PGTRWNED & TCRBJ2S7 \\
\hline 15 (CD8) & 9 & CASS & ZZDSBLFDD & TCRBJ1S1 \\
\hline 3 (CD8) & 12 & CASS & SGRYSSYD & TCRBJ1S1 \\
\hline 4 (CD8) & 12 & CASS & LFASERGP & TCRBJ1S1 \\
\hline 5 (CD8) & 12 & CASS & ESGLFERT & TCRBJ2S7 \\
\hline 6 (CD8) & 12 & CASS & SRLFGETFQ & TCRBJ1S1 \\
\hline 8 (CD8) & 12 & CASS & PPGSNQB & TCRBJ1S1 \\
\hline 9 (CD8) & 12 & CASS & PGIFGLF & TCRBJ2S7 \\
\hline 13 (CD8) & 12 & CASS & VSGSTVRT & TCRBJ1S1 \\
\hline 16 (CD8) & 12 & CASS & RDGSFYGTG & TCRBJ1S1 \\
\hline
\end{tabular}

\footnotetext{
${ }^{a}$ BV, TCR V $\beta$ family; J $\beta$ : joining region of TCR $V \beta$ CDR3; N-D-N, diversity region of TCR $V \beta C D R 3 ; \mathrm{V} \beta$, variable region of TCR $V \beta C D R 3$.

$\mathrm{b}$ underlined words show the conserved motif of TCR CDR3.
}

\section{Discussion}

Immune spectratyping has been used to assess TCR diversity for both healthy and disease states. Typically, the fragment lengths generated would have a Gaussian-like distribution. However, if clonal T cell expansion or a severe cytoreduction has occurred, the proportional distribution of different CDR3 lengths is affected. In previous studies, spectratyping has facilitated the identification of tumor-, pathogen-, or allo-antigen-driven oligoclonal expansions within the TCR repertoire (15-17).

In the present study, the CDR3 in CD4+ T cells and CD8+ $\mathrm{T}$ cells were spectratyped separately. This is in contrast with previous studies, where TCR CDR3 size diversity was analyzed in a combined population of CD4+ and CD8+ T cells obtained from patients with $\mathrm{CHB}(18,19)$.

In the present study, both monoclonal and oligoclonal expansion were detected for the CD8+ TCR V $\beta$ families of all the 18 patients examined. Moreover, the monoclonal expansion of CD8+ TCR V $\beta 5, V \beta 7, V \beta 9, V \beta 12$, and V $\beta 18$ families were found to be more prevalent than other TCR $\mathrm{V} \beta$ families. In contrast, the study of Yang et al. (11) to detect the oligoclonal expansion of T cells in CSHB patients demonstrated that TCR V $\beta 7$ and V $\beta 11$ were expressed more frequently compared to the other members of the TCR V $\beta$ family in PBMCs, and in CD8+ and CD8- subsets. It is possible that differences in the HLA types of the patients analyzed, as well as the HBV genotypes, HBV variants, and the detection methods used, may account for the differences observed between these studies.

Exogenous (plasma) HBV antigens can be processed by macrophage and presented to CD4+ T cells. This can enhance the synthesis of cytokines, which augment Tcell proliferation, thereby increasing the number of HLA class I molecules present on hepatocytes and decreasing viral replication. In the present study, monoclonal and oligoclonal expansion of CD4+ T cells was detected in $16 / 18$ patients. Furthermore, the average rate of monoclonal and oligoclonal expansion in CD4+ and CD8+ T cell subsets were 1.56 and 2.72, respectively. The number of monoclonal or oligoclonal expansion TCR V $\beta$ families in CD8+ T cells was significantly higher than that in CD4+ $T$ cells $(P<0.01)$, and this is consistent with the results of previous studies where proliferating HBV antigen-specific T cells were found to be CD8+ type (20). For a better understanding of the nature of $\mathrm{T}$ cells in disease presentation associated with HBV infection, monoclonal expansion of CD4+/CD8+ TCR V $\beta$ CDR3 was sequenced. As a result, highly conserved amino acid motifs were identified in the CD8+ TCR CDR3, and a higher frequency of BJ1S1 and $\mathrm{BJ} 2 \mathrm{~S} 7$ was identified in the proximal region of TCR CDR3. Several studies have shown that single viral or bacterial epitopes can induce T cell clones, including different TCR CDR3 sequences. It is possible that the pattern of CDR3 size distribution for TCR V $\beta$ in different CSHB patients may provide information regarding HBV antigens, especially if a certain CDR3 indicates that a particular peptide 
antigen of HBV was present. However, due to the diversity of HBV and human leukocyte antigens, $\mathrm{T}$ cells related to HBV were found to be different in CHB patients $(21,22)$.

$\mathrm{T}$ cells can identify several types of HBV antigens that have completely different structures. Therefore, it is reasonable to speculate that conserved sequences identified in an analysis of CDR3 sequences from a large number of CSHB patients may represent TCRs specific for a particular HBV antigen. For the CDR3 sequences analyzed from the 18 CSHB patients in the present study, three conserved amino acid motifs were identified, including GSF, LF, and GS. These motifs were present in the $\beta$-chains and may be involved in binding to a HBV antigen that is common to a number of CSHB patients. More studies are needed to further characterize the association between these conserved motifs and the corresponding antigen(s) present in CSHB patients, with the overall goal of elucidating the function of various TCR V $\beta$ gene families in the progression of CSHB.

In summary, the results of the present study provided evidence that peripheral CD4+ and CD8+ T cells from CSHB patients have undergone clonal expansion. The detection of pathogenic T cells in CSHB patients also provides useful insight regarding the pathogenesis and status of this disease. It is expected that the results of the present study would facilitate the development of DNA vaccines and individualized immunotherapies for $\mathrm{CHSB}$, in combination with future studies, to characterize the conserved motifs identified.

\section{Acknowledgements}

We thank Drs Ruo Lun Li, Hong Shi and Yao Wang for their assistance in collecting samples.

\section{Authors' Contribution}

Yan Tan developed the study concept and design, critical revision of the manuscript for important intellectual content, administrative, technical, and material supports. Ying Xiong contributed to acquisition of data, analysis and interpretation of data, and drafting the manuscript. Yu Guo Song was responsible for statistical analysis, and study supervision.

\section{Financial Disclosure}

The authors have no financial conflict to declare.

\section{Funding/Support}

This study was supported financially by the National Natural Science Foundation (c0302050302).

\section{References}

1. Lee WM. Hepatitis B virus infection. NEnglJMed.1997;337(24):173345.

2. McMahon BJ. Epidemiology and natural history of hepatitis B. Semin Liver Dis. 2005;25 Suppl 1:3-8.
3. Bathgate AJ, Garden OJ, Forsythe JR, Madhaven KK, Finlayson ND, Simpson KJ, et al. The outcome of the first 165 orthotopic liver transplants in Scotland. Scott Med J.1999;44(1):9-10.

4. Bektas M, Idilman R, Soykan I, Soydan E, Arat M, Cinar K, et al. Adjuvant therapeutic plasma exchange in liver failure: assessments of clinical and laboratory parameters. J Clin Gastroenterol. 2008;42(5):517-21.

5. Guidotti LG, Chisari FV. Immunobiology and pathogenesis of viral hepatitis. Annu Rev Pathol. 2006;1:23-61.

6. Xibing G, Xiaojuan Y, Zhonghua L, Juanhua W. Alteration in cellular immunity after chronic hepatitis B deteriorated into severe hepatitis and its significance. Hepat Mon. 2011;11(10):810-5.

7. Thimme R, Wieland S, Steiger C, Ghrayeb J, Reimann KA, Purcell $\mathrm{RH}$, et al. CD8(+) T cells mediate viral clearance and disease pathogenesis during acute hepatitis B virus infection. J Virol. 2003;77(1):68-76.

8. Manfras BJ, Rudert WA, Trucco M, Boehm BO. Analysis of the alpha/beta T-cell receptor repertoire by competitive and quantitative family-specific PCR with exogenous standards and high resolution fluorescence based CDR3 size imaging. J Immunol Methods. 1997;210(2):235-49.

9. Ma SW, Li YY, Zhang GW, Huang X, Sun J, Li C, et al. Complementarity-determining region 3 size spectratypes of $\mathrm{T}$ cell receptor beta chains in CD8+ T cells following antiviral treatment of chronic hepatitis B. Antimicrob Agents Chemother. 2011;55(2):888-94.

10. Ciupe SM, Devlin BH, Markert ML, Kepler TB. Quantification of total T-cell receptor diversity by flow cytometry and spectratyping. BMC Immunol. 2013;14:35.

11. Yang J, He J, Lu H, Wei L, Li S, Wang B, et al. Molecular features of the complementarity determining region 3 motif of the $\mathrm{T}$ cell population and subsets in the blood of patients with chronic severe hepatitis B. J Transl Med. 2011;9:210.

12. Soroosh P, Shokri F, Azizi M, Jeddi-Tehrani M. Analysis of T-cell receptor beta chain variable gene segment usage in healthy adult responders and nonresponders to recombinant hepatitis B vaccine. Scand J Immunol. 2003;57(5):423-31.

13. Imamura T, Yokosuka O, Kurihara T, Kanda T, Fukai K, Imazeki F, et al. Distribution of hepatitis B viral genotypes and mutations in the core promoter and precore regions in acute forms of liver disease in patients from Chiba, Japan. Gut. 2003;52(11):1630-7.

14. Kou ZC, Puhr JS, Rojas M, McCormack WT, Goodenow MM, Sleasman JW. T-Cell receptor Vbeta repertoire CDR3 length diversity differs within CD45RA and CD45RO T-cell subsets in healthy and human immunodeficiency virus-infected children. Clin Diagn Lab Immunol. 2000;7(6):953-9.

15. Ochsenreither S, Fusi A, Wojtke S, Busse A, Nussler NC, Thiel E, et al. Comparison of T-cell receptor repertoire restriction in blood and tumor tissue of colorectal cancer patients. $J$ Transl Med. 2010;8:35

16. Okajima M, Wada T, Nishida M, Yokoyama T, Nakayama Y, Hashida Y, et al. Analysis of T cell receptor Vbeta diversity in peripheral CD4 and CD8 T lymphocytes in patients with autoimmune thyroid diseases. Clin Exp Immunol. 2009;155(2):166-72.

17. Luo W, Su J, Zhang XB, Yang Z, Zhou MQ, Jiang ZM, et al. Limited $\mathrm{T}$ cell receptor repertoire diversity in tuberculosis patients correlates with clinical severity. PLoS One. 2012;7(10).

18. Sugyo S, Yuh K, Nakamura K, Emi K, Shijo H, Iida T, et al. An analysis of $\mathrm{T}$ cell antigen receptor variable beta genes during the clinical course of patients with chronic hepatitis B. J Gastroenterol Hepatol.1999;14(4):333-8.

19. Yao XS, Zhang GW, Ma L, Wen Q, Hou JL, Meng MJ, et al. Analysis of the CDR3 length of TCR alphabeta T cells in the peripheral blood of patients with chronic hepatitis B. Hepatol Res. 2006;35(1):10-8.

20. Das A, Hoare M, Davies N, Lopes AR, Dunn C, Kennedy PT, et al Functional skewing of the global CD8 T cell population in chronic hepatitis B virus infection. J Exp Med. 2008;205(9):2111-24.

21. Wai CT, Fontana RJ. Clinical significance of hepatitis B virus genotypes, variants, and mutants. Clin Liver Dis. 2004;8(2):321-52.

22. Maru Y, Yokosuka O, Imazeki F, Saisho H, Omata M. Analysis of $\mathrm{T}$ cell receptor variable regions and complementarity determining region 3 of infiltrating T lymphocytes in the liver of patients with chronic type B hepatitis. Intervirology. 2003;46(5):277-88. 